\title{
Staging of Bronchogenic Carcinoma at Tertiary Health Care Centre with Multidetector Computed Tomography and Histopathological Correlation
}

\author{
Dharma Raj Meena ${ }^{1}$, Chandraveer Singh Godara², Sangeeta Saxena ${ }^{3}$, Harsh vardhan ${ }^{4}$, Abhishek Gupta $^{5}$, \\ Bhajan lal ${ }^{6}$ \\ ${ }^{1}$ Professor and HOD, ${ }^{2}$ Resident Doctor, ${ }^{3}$ Senior Professor, ${ }^{4}$ Assistant Professor, ${ }^{5}$ Resident Doctor, ${ }^{6}$ Resident Doctor, Department \\ of Radio-diagnosis, Government Medical College, Kota, Rajasthan, India
}

Corresponding author: Dr. Chandraveer Singh Godara, Department of Radio-diagnosis, Government Medical College, Kota, Rajasthan, INDIA

DOI: http://dx.doi.org/10.21276/ijcmsr.2019.4.2.35

How to cite this article: Dharma Raj Meena, Chandraveer Singh Godara, Sangeeta Saxena, Harsh vardhan, Abhishek Gupta, Bhajan lal. Staging of Bronchogenic carcinoma at tertiary health care centre with multidetector computed tomography and histopathological correlation. International Journal of Contemporary Medicine Surgery and Radiology. 2019;4(2):B161-B165.

\section{A B S T R A C T}

Introduction: Bronchogenic carcinoma is most common cause of cancer-related mortality in the developed world with incidence rising in developing countries. MDCT is the modality of choice for evaluating the lung carcinomas. The objectives of our study were to assess the role of multi detector computed tomography in diagnosis, characterization and staging of lung cancer and their cytopathological correlation.

Material and Methods: Data was collected from 82 patients with clinically or radiologically suspected pulmonary mass lesion referred for CT scan of chest to Department of Radiodiagnosis GMC, Kota (Rajasthan). Collected data was analyzed based on the variables of the lung lesion seen on CT images followed by CT diagnosis and correlation made with histopathology report. Finally, only those patients with a cytopathologically confirmed diagnosis of lung cancer were included in the final analysis.

Results: The maximum prevalence of bronchogenic carcinoma was seen between 60-69 years of age (37.80\%) with male predominance (82.93\%). About $78.04 \%$ patients showed positive smoking history. Cough with expectoration (84.15\%) was the most common symptom. The most common histological presentation was Adenocarcinoma in 38 patients (46.34\%) followed by squamous cell carcinoma in 28 patients (34.14\%). Most common tumor among the males was squamous cell carcinoma and among females was adenocarcinoma.

Conclusion: CT is a highly sensitive (96.34\%) and highly specific (84.62\%) test with high positive predictive value (97.53\%) to diagnose Bronchogenic carcinoma in a sample suitably selected and referred for malignancy. MDCT is a useful tool in the staging of Bronchogenic Ca.

Keywords: Bronchogenic Carcinoma, Multi Detector Computed Tomography and CT/USG guided FNAC.

\section{INTRODUCTION}

A status report on the global burden of cancer worldwide using the GLOBOCAN 2018 estimates of cancer incidence and mortality produced by the International Agency for Research on Cancer, with a focus on geographic variability across 20 world regions. There will be an estimated 18.1 million new cancer cases (17.0 million excluding nonmelanoma skin cancer) and 9.6 million cancer deaths (9.5 million excluding nonmelanoma skin cancer) in 2018.

In both sexes combined, lung cancer is the most commonly diagnosed cancer ( $11.6 \%$ of the total cases) and the leading cause of cancer death (18.4\% of the total cancer deaths), closely followed by female breast cancer (11.6\%), prostate cancer $(7.1 \%)$, and colorectal cancer $(6.1 \%)$ for incidence and colorectal cancer (9.2\%), stomach cancer (8.2\%), and liver cancer $(8.2 \%)$ for mortality.
Lung cancer is the most frequent cancer and the leading cause of cancer death among males, followed by prostate and colorectal cancer (for incidence) and liver and stomach cancer (for mortality). Among females, breast cancer is the most commonly diagnosed cancer and the leading cause of cancer death, followed by colorectal and lung cancer (for incidence), and vice versa (for mortality).

\section{Burden of the disease in India}

It is the second most common cancer in men and the fifth most common cancer in both men and women together.

\section{MATERIAL AND METHODS}

This prospective study was conducted from May 2017 to April 2019 (Two year). 53 patients with clinical or radiological suspicion of bronchogenic carcinoma referred for CT scan of thorax to the Department Of Radio Diagnosis, Government 
Medical College Kota (Rajasthan) will be taken.

\section{Inclusion criteria}

Patients with clinically or radiologically suspected bronchogenic carcinoma.

Patients in whom histopathological correlation is available.

\section{Exclusion criteria}

Patients in whom histopathological correlation is not available.

Severely debilitated patient

Renal impairment

Allergic to contrast media

Previously diagnosed cases of bronchogenic carcinoma who were treated and now comes with recurrence.

\section{Method of collection of data}

Data will be collected from cases of suspected bronchogenic carcinoma referred for CT scan of thorax by purposive sampling using a proforma.

All scans are done using GE bright speed 16 slice MDCT with $120 \mathrm{KVp}$ and $300 \mathrm{mAs}$ with $5 \mathrm{~mm}$ section thickness, retro reconstruction of $0.625 \mathrm{~mm}$ section thickness and reformation. Contrast study is done using $70-80 \mathrm{ml}$ of $350 \mathrm{mg} / \mathrm{ml}$ non-ionic iodinated contrast, injected using pressure injector at the rate of $3-4 \mathrm{ml} / \mathrm{s}$. Lung lesions are characterised based on the site, size, enhancement pattern, presence of calcification, cavitation, involvement of the hila, pleura, chest wall or mediastinum MDCT findings are correlated with histopathological examination of the specimen obtained from FNAC / biopsy of the lesion.

\section{Equipment}

CT is performed with multi-slice CT scanner GE Bright Speed 16.

\section{STATISTICAL ANALYSIS}

Collected data were analysed based on the variables of the lung lesion seen in CT images as already mentioned followed by CT diagnosis and staging and correlation made with histopathology report. As the study design is diagnostic test evaluation, collected data were analysed by calculating sensitivity, specificity, positive predictive value, negative predictive.

\section{RESULTS}

This study was conducted in the Department of Radiodiagnosis, Government Medical College Kota (Rajasthan) from May 2017 to April 2019. The study comprised of a total of 82 patients.

Among the 82 patients included in this study, $17.07 \%$ were females $(n=14)$ and $82.93 \%$ were males $(n=68)$. Hence we can conclude that bronchogenic carcinoma has got a more male preponderance over females.

The age distribution of patients with Bronchogenic carcinoma in our study was between the age group of 40-89 years with a mean age of 65 years. $37.80 \%$ of the patients were in the age group of $60-69$ years $(n=31), 31.71 \%$ were in the age group of $59-59$ years $(n=26)$. Thus we have observed that Bronchogenic carcinoma is more common in the age group of 60-69 years and secondly in age group of 50-59 years.

In our study involving eighty two patients, $84.15 \%$ of patients had cough with expectoration $(n=69), 58.54 \%$ patients had weight loss $(n=48), 62.20 \%$ patients had anorexia $(n=51)$, $52.44 \%$ patients had chest pain $(n=43), 39.02 \%$ patients had dyspnea $(n=32)$ and $23.17 \%$ patients had hemoptysis $(n=19)$. Therefore from our study it was evident that cough followed by anorexia and weight loss were the most common symptoms of patients with bronchogenic carcinoma.

In our study $52.44 \%$ lesions were peripheral in location ( $\mathrm{n}=$ 43 ) and $47.56 \%$ of lesions were central in location $(n=39)$.

In our study of eighty two patients with bronchogenic carcinoma distant metastasis of Bronchogenic carcinoma were seen in 26 patients $(31.70 \%)$. Liver is most common site of metastasis with 13 patients (15.85\%) followed by bone in 9 patients (10.97\%), adrenal in 8 patients $(09.76 \%)$ and peritoneum in 2 patient $(02.44 \%)$ respectively.

In our study of eighty two patients with bronchogenic carcinoma, it revealed that the $82.93 \%$ of patients had mediastinal lymph nodes ( $\mathrm{n}=68), 62.20 \%$ had subcarinal lymph nodes $(\mathrm{n}=51), 54.88 \%$ had hilar lymph nodes $(\mathrm{n}=45)$ and $03.66 \%$ had supraclavicular lymph nodes $(n=3)$. Hence mediastinal lymphadenopathy is the most common type of lymph node involvement in patients with bronchogenic carcinoma.

In our study of eighty two patients with bronchogenic carcinoma the distribution of various histological types of bronchogenic carcinoma is as follows; $46.34 \%$ of patients had adenocarcinoma $(n=38), 34.14 \%$ patients had squamous cell carcinoma $(n=28), 11.04 \%$ patients had small cell carcinoma $(n=11), 06.10 \%$ patients had undifferentiated large cell carcinoma $(n=5)$. Thus in our study it indicates that adenocarcinoma is most common type of Bronchogenic carcinoma.

$74.39 \%$ of patients in our study were diagnosed with T4 stage of the tumor at the time of presentation. $19.51 \%$ had T3 stage tumor at the time of presentation, $03.66 \%$ had T2b stage of tumor, $02.44 \%$ had T2a stage of tumor and no patient recorded in $\mathrm{T} 1 \mathrm{a}, \mathrm{T} 1 \mathrm{~b}$ and $\mathrm{T} 1 \mathrm{c}$ stages of tumor.

$57.31 \%$ of patients in our study were in N2 stage at the time of diagnosis, $26.83 \%$ were in N3 stage, $10.97 \%$ were in N0 stage and $04.88 \%$ was in N1 stage.

$36.58 \%$ of patients in our study were in M1a stage with tumor in contralateral lung or pleural/ pericardial nodule/ malignant effusion, $32.93 \%$ were in M0 stage with no evidence of metastases, $19.51 \%$ were in M1c stage with evidence of multiple extra-thoracic metasteses and $10.98 \%$ were in M1b stage with single extrathoracic metastasis intrapulmonary/ pleural metastasis or malignant pleural / pericardial effusion.

\section{Accuracy of MDCT in evaluation of bronchogenic carcinoma}

\section{Comparison of CT diagnosis with Histopathological diagnosis of bronchogenic carcinoma}

These (table-1,2) validity tests shows CT is a highly sensitive (96.34\%) and highly specific (84.62\%) test and also has a high positive predictive value (97.53\%) to diagnose Bronchogenic carcinoma.

Multi Detector Computed Tomography has a high positive predictive value suggestive of great diagnostic accuracy in the 


\begin{tabular}{|l|l|c|c|c|}
\hline \multirow{2}{*}{\multicolumn{2}{|c|}{}} & \multicolumn{3}{|c|}{$\begin{array}{c}\text { Histo-pathological diagnosis for } \\
\text { Bronchogenic carcinoma }\end{array}$} \\
\cline { 3 - 5 } \multicolumn{2}{|c|}{} & Yes & No & Total \\
\hline $\begin{array}{l}\text { CT diagnosis for } \\
\text { Bronchogenic } \\
\text { Carcinoma }\end{array}$ & Yes & $\begin{array}{c}79 \text { (True } \\
\text { positive) }\end{array}$ & $\begin{array}{c}\text { 02 (False } \\
\text { positive) }\end{array}$ & 81 \\
\cline { 2 - 5 } & No & $\begin{array}{c}03 \text { (False } \\
\text { negative) }\end{array}$ & $\begin{array}{c}11 \text { (True } \\
\text { negative) }\end{array}$ & 14 \\
\hline Total & & 82 & 13 & 95 \\
\hline
\end{tabular}

Table-1(A): Sensitivity, Specificity, Positive predictive value, Negative predictive value and accuracy of CT to diagnose Bronchogenic carcinoma

\begin{tabular}{|l|c|}
\hline Validity Test & Percent \\
\hline Sensitivity & $96.34 \%$ \\
\hline Specificity & $84.62 \%$ \\
\hline Positive predictive value & $97.53 \%$ \\
\hline Negative predictive value & $78.57 \%$ \\
\hline Accuracy Table-1(B): Validity Tests Value \\
\hline \multicolumn{2}{|c|}{ 94.74\% } \\
\hline
\end{tabular}

evaluation of Bronchogenic Carcinoma.

\section{Comparison between adenocarcinoma and squamous cell carcinoma}

$50.94 \%$ of male patients had adenocarcinoma $(n=25)$ and $49.06 \%$ of male patients had squamous cell carcinoma ( $\mathrm{n}$ = 26). $84.62 \%$ of female patients had adenocarcinoma ( $\mathrm{n}=$ 13) and $15.38 \%$ of the female patients had squamous cell carcinoma $(\mathrm{n}=02)$.

Chi squared equals 4.846 with 1 degrees of freedom. The onetailed $\mathrm{P}$ value equals 0.0139 is considered to be statistically significant.

Hence from our study it is evident that adenocarcinoma is more commonly seen in female patients and squamous cell carcinoma is more commonly seen in male patients.

$46.88 \%$ of patients with central lesions had adenocarcinoma $(\mathrm{n}=15)$ and the remaining $53.12 \%$ had squamous cell carcinoma $(n=17) \cdot 67.65 \%$ of patients with peripheral lesions had adenocarcinoma ( $\mathrm{n}=23$ ) and $32.35 \%$ had squamous cell carcinoma $(n=11)$. Chi squared equals 2.912 with 1 degrees of freedom. The one-tailed $\mathrm{P}$ value equals 0.0440 is considered to be statistically significant.

Hence from our study it is evident that adenocarcinoma is more commonly seen in peripheral location and squamous cell carcinoma is more commonly seen in central location.

Out of the non-smokers, $86.67 \%$ had adenocarcinoma (n $=13)$ and $13.33 \%$ had squamous cell carcinoma $(\mathrm{n}=01)$. Chi squared equals 6.726 with 1 degrees of freedom. The one-tailed $\mathrm{P}$ value equals 0.0048 is considered to be very statistically significant.

Thus it can be concluded that adenocarcinoma commonly affects non-smokers and squamous cell carcinoma is more commonly seen in smokers

\section{DISCUSSION}

In present study of 82 patients, the study group is divided into five age groups (decades) 40 to 49 years, 50 to 59 years, 60 to 69 years, 70 to 79 years and $80-89$ years. It was observed that maximum $31(37.80 \%)$ patients were in the 60 to 69 years age group while age group 50 to 59 years constituting $26(31.71 \%)$ patients and 70 to 79 years constituting 13 (15.85\%) of patients. This is concordance with study by Saket RK et al ${ }^{1}$ (2016) and Hathila $\mathrm{N}$ et al ${ }^{2}$ (2016) this study is contrary to study done by Narayanswamy I et $\mathrm{al}^{3}$ (2015) Yadav D et $\mathrm{al}^{4}$ (2016) and Dr. Babu S et $\mathrm{al}^{5}$ (2016).

Male to female ratio is 4.85:1 in our study which is similar to the study of Malik PS et al ${ }^{6}$ (2013), Saket RK et al ${ }^{1}$ (2016), Shah D et al ${ }^{7}$ (2017) and Biswas P et al ${ }^{8}$ (2016).

Bronchogenic carcinoma is seen more commonly in smokers (78.05\%) than non-smokers (21.95\%). Similar observations have been reported by Shetty CM et $\mathrm{al}^{9}$ (2005), Rawat J et $\mathrm{al}^{10}$ (2009), Saket RK et al ${ }^{1}$ (2016), Yadav D et al ${ }^{4}$ (2016) and Parvaiz AK et a $1^{11}$ (2010).

In our study there is evidence of a strong association between the occurrence of smoking and squamous cell carcinoma. Similar results were obtained in study by Krishnamurthy A et $\mathrm{al}^{12}$ (2012) and Arora VK et $\mathrm{al}^{13}$ (1990).

Our study showed that adenocarcinoma is commonly seen in non- smokers. This is in agreement with the study by Dey A et $\mathrm{al}^{14}$ (2012), Behera D et al ${ }^{15}$ (2004), Shetty CM et al ${ }^{9}$ (2005) and Krishnamurthy A et al ${ }^{12}$ (2012).

Cough is the most common presenting complaint among patients in our study (84.15\%) followed by loss of appetite (62.20), loss of weight (58.54\%) and chest pain (52.44\%). This is concordance with study by Saket RK et $\mathrm{al}^{1}$ (2016), Yadav D et al ${ }^{4}$ (2016), Hathila N et al ${ }^{2}$ (2016), Quamrul M et $\mathrm{al}^{16}(2010)$.

\section{Tumour characteristics}

In our study it was found that the lesions were slightly more peripherally located $(52.44 \%)$ and the rest were found in a central location $(47.56 \%)$. This is in concordance with the study done by Vigg A et al ${ }^{17}$ (2003), Dr Adaikkalavan C et $\mathrm{al}^{18}$ (2017), Biswas $\mathrm{P}$ et $\mathrm{al}^{8}$ (2016) and Narayanswami I et $\mathrm{al}^{3}$ (2015) where peripheral lesions are found to be more common than central lesions.

$62.20 \%$ of cases in our study have a spiculated contour which is concordance to the study by Shetty CM et $\mathrm{al}^{9}$ (2005), Dr. Adaikkalavan C et $\mathrm{al}^{18}$ (2017), Yadav D et $\mathrm{al}^{4}$ (2016) and Biswas $\mathrm{P}$ et al ${ }^{8}$ (2016).

All 100\% cases showed heterogeneous contrast enhancement. This is concordance with the study by Dr Adaikkalavan C et $\mathrm{al}^{18}$ (2017), Hathila $\mathrm{N}$ et $\mathrm{al}^{2}$ (2016) and Shah $\mathrm{D}$ et $\mathrm{al}^{7}$ (2017).

$301.70 \%$ of patients in our study had distant (extrathoracic) metastasis at the time of presentation. This is in concordance with the study by Saket RK et $\mathrm{al}^{1}$ (2016).

In our study the most common site for metastasis was seen to be liver $(15.85 \%)$ followed by bone $(10.97 \%)$. This is concordance with study by Shah D et $\mathrm{al}^{7}(2017)$, Dr. Modi $\mathrm{M}$ et $\mathrm{al}^{19}$ (2016) and Sawhney $\mathrm{M}$ et $\mathrm{al}^{20}$ (2017).

Mediastinal lymph node involvement was seen in $82.93 \%$ of cases with bronchogenic carcinoma in our study. Similar findings were seen in studies by Yadav D et al ${ }^{4}$ (2016).

In the present study, majority of patients were diagnosed at latter stage of disease. The majority of Bronchogenic carcinoma patients had advanced stage disease (IIIB and IV). Similar observation reported by Prasad R et al ${ }^{21}$ (2009), Malik PS et al ${ }^{6}$ (2013), and Shah D et al ${ }^{7}$ (2017). 


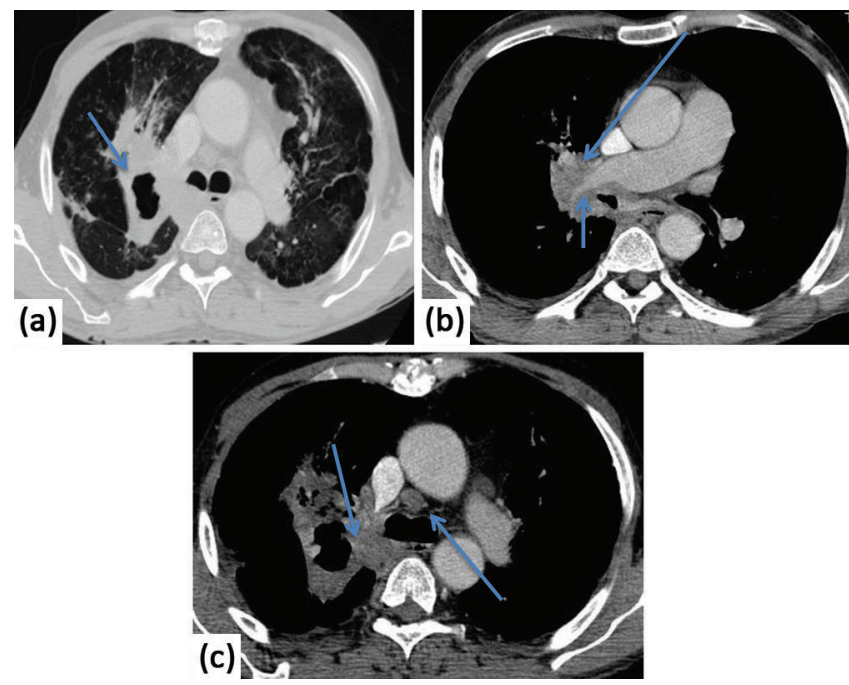

Figure-1: (a). CECT chest axial view in lung window showing cavitatory mass lesion in right lung with mediastinal infiltration; (b). CECT chest axial view showing narrowing of right main bronchus and right pulmonary artery invasion; (c). CECT chest axial plane showing metastatic lymphnode in pre tracheal region, On HPE, mass was diagnosed as squamous cell carcinoma.

\section{Histopathology}

In our study adenocarcinoma was seen to be the most common histological subtype accounting for $46.34 \%$ of cases. This is in concordance with the study by Malik PS et $\mathrm{al}^{6}$ (2013), Krishnamurthy A et $\mathrm{al}^{12}$ (2012), Shad D et al ${ }^{7}$ (2017), Dr. Modi M et $\mathrm{al}^{19}$ (2016) and Dr. Babu S et $\mathrm{al}^{5}$ (2016) which showed an increasing trend in the incidence of adenocarcinoma.

However, our findings are contrary to the studies done by Dr. Adaikkalavan et al ${ }^{18}$ (2017), Rawat J et al ${ }^{10}$ (2009), Saket RK et $\mathrm{al}^{1}$ (2016) and Yadav D et al ${ }^{4}$ (2016) which revealed that squamous cell carcinoma was the most common histological subtype followed by adenocarcinoma.

\section{CONCLUSION}

$\mathrm{CT}$ is a highly sensitive and highly specific test and also has a high positive predictive value to diagnose Bronchogenic carcinoma. Multi Detector Computed Tomography has a high positive predictive value suggestive of great diagnostic accuracy in the evaluation of Bronchogenic Carcinoma. There is significant correlation with the MDCT diagnosis of Bronchogenic carcinoma with that of histopathology. Computed tomography is the most sensitive and noninvasive imaging modality that provides valuable information of the tumor characteristics and its extent. MDCT is a useful tool in the staging of Bronchogenic Carcinoma.

\section{Case-1}

58 years old male came with cough with expectoration, dyspnea and hemoptysis since 8 months.

\section{REFERENCES}

1. Rajesh Kumar Saket et al. Role of Multi-Detector Computed Tomography Imaging In Patients with Clinically Suspected Lung Cancer in Kumaun Region of Uttarakhand (India) JMSCR 2016;4(1):23-29.

2. Hathila N, Goswami D. Radiological evaluation of various types of primary Bronchogenic carcinoma: a study of 65 cases. Int J Med Sci Public Health 2016; 5 (6):919-23.

3. Narayanaswamy I, Jayaram N, Ashwathappa S. Multidetector Row Computed Tomography (MDCT) Evaluation of Bronchogenic Carcinoma And Histopathological Correlation. IJMI, 2015; 3(4): 82-83.

4. Yadav D, Yadav N, Goyal R, Romana M. Role of multidetector computed Tomography in evaluation of suspected bronchogenic carcinoma. Int J Res Med Sci 2016; 4 (2):829-35.

5. Babu S et al. Multidetector CT Evaluation of Neoplastic Lung Lesions with Image Guided Transthoracic Tissue Sampling. (IOSR-JDMS) 2016;15 (4):50-53.

6. Malik PS et al. Clinico-pathological Profile of Lung Cancer at AIIMS: A Changing Paradigm in India Asian Pacific J Cancer Prev, 14 (1), 489-494.

7. Shah D, Shastri M, Patel D, Diwanji N, Desai E, Chitara M. Diagnosis and staging of lung carcinoma with CT scan and its histopathological correlation. Int J Res Med Sci 2017;5 (3):2346-52.

8. Biswas P, Datta A, De A, Sinha LK. Pulmonary Mass Lesions: CT Scan Diagnostic-Impressions and FNAC Diagnoses A Correlative Study. Int J Med Res Rev 2016;4 (6):1052-1062.

9. Shetty CM, Lakhkhar BN, Gangadhar VSS, Ramachandran NR. Changing Pattern Of Bronchogenic Carcinoma: A Statistical Variation Or Reality. Ind J Radiol Imag 2005 15:1:233-238.

10. Jagdish R, Girish S, Dushyant G, Ruchi D, Sunil S. Clinico-pathological profile of lung cancer in Uttarakhand. Lung India. 2009; 26(3): 74-76.

11. Parvaiz AK, Satish KK, Mohammad MS, Reyaz A, Tasleem, Azra S. Lung Cancer In The Kashmir Valley. Lung India 2010; 27(3): 131-137.

12. Krishnamurthy A, Vijayalakshmi R, Gadigi V, Ranganathan R, Sagar TG. The relevance of "Nonsmoking-associated lung cancer" in India: A single-centre experience. Indian J Cancer 2012;49 (5):82-8

13. Arora VK, Seetharaman M.L, Ramkumar S et al. Bronchogenic Carcinoma - Clinicopathological Pattern In South Indian Population, Lung India 1990;7 (4): 133 $-138$.

14. Dey A, Biswas D, Saha SK, Kundu S, Kundu S, Sengupta A. Comparison study of clinicoradiological profile of primary lung cancer cases: An Eastern India experience. Indian J Cancer 2012;49 (1):89-95

15. Behera $\mathrm{D}$ and Balamugesh T. Lung Cancer In India, Indian J Chest Dis Allied Sci 2004; 46(6): 269-281.

16. Quamrul $\mathrm{M}$ et al. Clinico-Pathological Profile Of Bronchogenic Carcinoma In a Tertiary Care Hospital In Bangladesh, Journal of Chittagong Medical College Teachers' Association 2010; 21 (1): 45 - 49.

17. Vigg A et al Pattern Of Lung Cancer In Elderly, J Assoc Physicians India October 2003; 53(4): 963 - 965.

18. Adaikkalavan C, Sajitha K, Verghese J, Varghese AE. Role of Computed Tomography in Diagnosis of Bronchogenic Carcinoma with Histopathological Correlation. JMSCR, 2017;5 (3):116-20. 
19. Modi $\mathrm{m}$ et al. Histopathological and CT Imaging Correlation of Various Primary Lung Carcinoma. (IOSR-JDMS). 2016;15 (6):104-110.

20. Sawhney M, Chauhan N, Saini M, Khanduri R. Clinico-radiological and pathological correlation of lung cancer patients presenting to a tertiary care centre J. Evid. Based Med. Healthc. 2017;4 (1):23-29.

21. Prasad R, Verma SK, Sanjay. Comparison between young and old patients with bronchogenic carcinoma. J Can Res Ther 2009;5 (3):31-5.

Source of Support: Nil; Conflict of Interest: None

Submitted: 09-05-2019; Accepted: 10-06-2019; Published online: 30-06-2019 